\title{
Reflexões sobre o desafio ambiental: níveis de eutrofização e floração de cianobactérias na Bacia Apodi-Mossoró
}

Um problema recorrente encontrado em alguns reservatórios de água calma da região Nordeste do Brasil é o processo de eutrofização, que corresponde ao aumento na concentração de nutrientes na água. Isso contribui no crescimento da biomassa fitoplanctônica, levando a redução na transparência da água interferindo na estrutura física e química dos ecossistemas aquáticos que resultam em condições favoráveis para florações de cianobactérias. Portanto, este trabalho teve como objetivo analisar o Índice do Estado Trófico (IET) e as concentrações de cianobactérias nos reservatórios Açude Pau dos Ferros, Açude de Lucrécia e Açude Rodeador, além disso, promover uma reflexão teórica sobre a questão ambiental ligada a esses recursos hídricos. As informações sobre o IET nos reservatórios fundamentaram em dados secundários, disponibilizados pelo Programa Água Azul, que realizou o monitoramento das águas superficiais da Bacia Hidrográfica do Rio Apodi-Mossoró, entre os anos de 2008 e 2016. Os dados do monitoramento demonstraram que o Açude Pau dos Ferros foi o que apresentou o maior IET, categorizado com média Hipereutrófico, enquanto os açudes Lucrécia e Roeador ficou com média Supereutrófico. Os dados sobre densidade de cianobactérias se mostraram quase em sua totalidade, acima das normas que preconizam os limites máximos permitidos, de acordo com Portaria $2914 / 2011$ do Ministério da Saúde e da Resolução 257/2005 do CONAMA. As ocorrências desses componentes revelam o risco socioambiental, tendo em vista que esses açudes são usados para abastecimento humano. Em suma, a teoria social dispõe de conceitos que contribuem na reflexão teórica sobre a questão do meio ambiente dentro da perspectiva do desafio ambiental, no qual tem revelado que muitas problemáticas de ordem ecológica, como é o caso da eutrofização que tem ligação com as atividades humanas que estão pautadas na lógica da globalização da natureza, colocando em risco as espécies biológicas que estão diretamente dependentes desse recurso.

\section{Reflections on the environmental challenge: levels of eutrofization and flowering of cyanbacteria in the Apodi-Mossoró Basin}

\begin{abstract}
A recurring problem found in some calm water reservoirs in Northeast Brazil is the eutrophication process, which corresponds to an increase in the concentration of nutrients in the water. This contributes to the growth of phytoplankton biomass, leading to a reduction in water transparency, interfering in the physical and chemical structure of aquatic ecosystems that result in favorable conditions for cyanobacterial blooms. Therefore, this study aimed to analyze the Trophic State Index (EIT) and cyanobacteria concentrations in the Açude Pau dos Ferros, Açude de Lucrécia and Açude Rodeador reservoirs, in addition to promoting a theoretical reflection on the environmental issue related to these resources water resources. The information about the EIT in the reservoirs was based on secondary data, made available by the Água Azul Program, which carried out the monitoring of the surface waters of the Apodi-Mossoró River Basin, between the years 2008 and 2016. The monitoring data showed that the Weir Pau dos Ferros was the one with the highest EIT, categorized with Hypereutrophic average, while Lucrécia and Roeador weirs had Supereutrophic average. The data on cyanobacteria density were shown almost entirely, above the standards that advocate the maximum permitted limits, according to Ordinance 2914/2011 of the Ministry of Health and CONAMA Resolution 257/2005. The occurrence of these components reveals the socio-environmental risk, given that these dams are used for human supply. In short, social theory has concepts that contribute to theoretical reflection on the issue of the environment within the perspective of the environmental challenge, in which it has revealed that many ecological issues, such as eutrophication that is linked to activities that are guided by the logic of the globalization of nature, putting at risk the biological species that are directly dependent on this resource.
\end{abstract}

Keywords: Cyanobacteria; Phytoplankton; Water quality.

Topic: Desenvolvimento, Sustentabilidade e Meio Ambiente

Reviewed anonymously in the process of blind peer.

Carmem Sara Pinheiro de Oliveira (iD)

Universidade Federal do Rio Grande do Norte, Brasil http://lattes.cnpq.br/1983398735995533

http://orcid.org/0000-0001-9896-3144

sarinhac.s@hotmail.com

Aleson da Silva Fonseca (in)

Universidade Federal do Rio Grande do Norte, Brasil

http://lattes.cnpq.br/7428339911970142

http://orcid.org/0000-0002-7148-9208

fonseca.aleson@gmail.com

\section{Carlos Andrés Díaz (iD}

Universidade Federal do Rio Grande do Norte, Brasil

http://lattes.cnpq.br/7004800951204046

http://orcid.org/0000-0002-6759-6668

carpp930703@gmail.com

6

DOI: 10.6008/CBPC2179-6858.2020.005.0047
Received: 10/08/2020

Approved: 21/09/2020

Wagner Pereira dos Santos

Universidade Federal do Rio Grande do Norte, Brasil http://lattes.cnpq.br/5597069460243330

http://orcid.org/0000-0002-7672-6049

wagnerpds5@gmail.com
Referencing this:

OLIVEIRA, C. S. P.; FONSECA, A. S.; DÍAZ, C. A.; SANTOS, W. P. Reflexões sobre o desafio ambiental: níveis de eutrofização e floração de cianobactérias na Bacia Apodi-Mossoró. Revista Ibero Americana de Ciências Ambientais, v.11, n.5, p.519-530, 2020. DOI: http://doi.org/10.6008/CBPC2179-6858.2020.005.0047 


\section{INTRODUÇÃO}

Um problema recorrente encontrado em alguns reservatórios de água calma é o processo de eutrofização que é o aumento na concentração de nutrientes na água causa um crescimento na biomassa fitoplanctônica, e consequentemente uma redução na transparência da água, interferindo na estrutura física e química dos ecossistemas aquáticos que resultam em condições favoráveis para florações de cianobactérias. Segundo a Portaria n².914, de 12 de Dezembro de 2011 do Ministério de Saúde, as florações constantes de cianobactérias representam o maior problema relacionado à perda da qualidade da água de lagos e reservatórios eutrofizados, tornando esses ambientes impróprios para o abastecimento humano e outros usos, além da possibilidade de trazer riscos à saúde humana, a partir de toxinas produzidas por esses organismos (BRASIL, 2011).

Na região semiárida do Nordeste do Brasil situa-se entre $2,5^{\circ} \mathrm{S}$ e $16,1^{\circ} \mathrm{S}$ e $34,8^{\circ} \mathrm{W}$ e $46^{\circ} \mathrm{W}$, com uma área de cerca de $1.542 .000 \mathrm{~km}^{2}$, ou cerca de $18,26 \%$ da área do Brasil, e é a mais densamente populosa entre as terras secas do mundo, com mais de 53 milhões de habitantes, ou aproximadamente 34 habitantes por $\mathrm{km}^{2}$. Os cenários globais e regionais de mudanças climáticas no futuro indicam que a região poderia ser afetada pelo déficit de chuvas e aumento da aridez no próximo século; Essas condições climáticas favorecem o aumento da turbidez, a concentração de nutrientes e o aumento da biomassa de algas, que associada à poluição causa uma diminuição na qualidade da água e o estabelecimento de um cenário permanente de eutrofização em reservatórios.

O regime hidrológico peculiar, secas prolongadas, alternadas por curtos períodos de chuva, com baixo volume anual ( 400mm), alta taxa de irradiação e evaporação, longo tempo de residência na região, vêm causando uma ameaça à biodiversidade, levando a mudanças na dinâmica dos ambientes naturais e também em todas as comunidades que dependem ou vivem nesses corpos de água.

É por isso, que o acesso à água vem sendo um motivo de preocupação por parte da sociedade, onde os reservatórios são utilizados para diversos fins, como geração de energia elétrica, irrigação, navegação, lazer e abastecimento de água, que podem acabar afetando negativamente as características funcionais e estruturais dos ecossistemas em açudes da bacia Apodi-Mossoró, tais como os parâmetros físico-químicos, a morfometria e biológicas.

Por outro lado, os poluentes agrícolas, urbanos e industriais para os rios que leva à deterioração dos recursos hídricos, também o uso e ocupação do solo sem planejamento podem aumentar às ações antropogênicas que causam mudanças na qualidade da água local e induzem sua poluição. A qualidade da água reflete os efeitos agregados de vários processos que ocorrem ao longo do fluxo da água e são influenciados pelas características da bacia hidrográfica. Portanto, é importante avaliar a qualidade da água para se adequar ao seu respectivo uso.

Para mitigar os problemas ambientais gerados por condições inadequadas gestão de recursos hídricos, o primeiro passo é desenvolver métodos para um diagnóstico eficaz, embora os parâmetros físicoquímicos da água sejam bons estimadores do nível de poluição dos ecossistemas aquáticos, eles ignoram as 
comunidades biológicas, que resulta em uma avaliação momentânea, insuficiente para diagnosticar a qualidade ecológica dos ecossistemas aquáticos (MEDEIROS et al., 2018).

Neste sentido, a biotecnologia também oferece ferramentas que permitem a deteç̧ão de compostos tóxicos (biomonitoramento) e descontaminação do meio ambiente utilizando microrganismos e plantas (biorremediação), considerando que o fósforo, é geralmente, o elemento mais limitante para o crescimento do fitoplâncton em lagos e reservatórios temperados e tropicais, a melhor forma de minimizar os efeitos da eutrofização é controlar a entrada desse nutriente no sistema. Mostrando a necessidade de se retirar ou reduzir as fontes externas dos nutrientes, mas também reduzir o retorno do fósforo para a coluna d'água.

Diante do exposto, este trabalho teve como principal objetivo analisar o Índice do Estado Trófico (IET) e as concentrações de cianobactérias nos reservatórios Açude Pau dos Ferros, Açude de Lucrécia e Açude Rodeador, usados para abastecimento humano no semiárido potiguar, além disso, promover uma reflexão teórica sobre a questão ambiental ligado a esses recursos hídricos.

\section{METODOLOGIA}

As coletas das águas superficiais foram efetuadas durante os anos de 2008 e 2016 na Bacia Hidrográfica do Rio Apodi-Mossoró. Em sua totalidade, a bacia possui extensão de 210.000 km², situada no Estado do Rio Grande do Norte, no qual ocupa uma área com cerca de $14.276 \mathrm{~km}^{2}$ (SEMARH, 2006). Uma vez que os reservatórios que se localizam no semiárido são influenciados pelos períodos chuvosos, os resultados aqui expostos são apresentados em comparação com o VLP (Valor Limite Permitido) para Classe 2 do CONAMA 357/2005 e Portaria 2914/2011 do Ministério da Saúde.

Este estudo foi realizado por meio da discussão de dados quali-quantitativos oriundos do Programa Água Azul. Esse programa foi viabilizado mediante parcerias do governo entre órgãos públicos do Estado do Rio Grande do Norte: Secretaria de Meio Ambiente e Recursos Hídricos do Rio Grande do Norte - SEMARH, Instituto de Desenvolvimento Sustentável e Meio Ambiente do RN - IDEMA, Instituto de Gestão das Águas do Estado do Rio Grande do Norte - IGARN, Empresa de Pesquisa Agropecuária do Estado do Rio Grande do Norte-EMPARN, Universidade Federal do Rio Grande do Norte - UFRN, Universidade Estadual do Rio Grande do Norte - UERN, Instituto Federal de Educação, Ciência e Tecnologia - IFRN.

O Programa Água Azul realiza o acompanhamento periódico de vários pontos, no qual as Instituições responsáveis pelas análises foram o IGARN e a EMPARN, enquanto a amostragem foi realizada apenas pelo IGARN. Para este trabalho, foram analisadas apenas as informações correspondentes aos reservatórios: Açude Pau dos Ferros, localizado no município de Pau dos Ferros, Açude de Lucrécia, localizado na cidade de Lucrécia, e Açude Rodeador, situado em Umarizal.

Para a avaliação da eutrofização nos reservatórios de água para consumo humano do interior do estado, foi utilizado o Índice de Estado Trófico (IET) proposto por Carlson e modificado por Lamparelli (2004) (Tabela 1), onde foi utilizado 'Clorofila a' e 'Fósforo Total', por meio das seguintes equações:

Reservatórios:

$$
\text { IETCL }=10 * 6-0,92-0,34 * \ln C L \ln 2
$$


IETPT $=10 * 6-1,77-0,42 * \ln$ PT $\ln 2$

$\mathrm{IET}=\mathrm{IET}$ PT + IET CL2

Onde:

PT: concentração de fósforo total; $\mathrm{CL}$ : concentração de clorofila a; In: logaritmo natural.

Tabela 1: Características e classificação do nível do Estado Trófico.

\begin{tabular}{|c|c|c|}
\hline $\begin{array}{l}\text { Valor } \\
\text { do IET }\end{array}$ & $\begin{array}{l}\text { Classes de Estado } \\
\text { Trófico }\end{array}$ & Características \\
\hline$=47$ & Ultraoligotrófico & $\begin{array}{l}\text { Corpos d'água limpos, de produtividade muito baixa e concentrações insignificantes de nutrientes } \\
\text { que não acarretam em prejuízos aos usos da água. }\end{array}$ \\
\hline $\begin{array}{ll}47 & < \\
\mathrm{IET} & = \\
52 & \end{array}$ & Oligotrófico & $\begin{array}{l}\text { Corpos d'água limpos, de baixa produtividade, em que não ocorrem interferências indesejáveis } \\
\text { sobre os usos da água, decorrentes da presença de nutrientes. }\end{array}$ \\
\hline $\begin{array}{l}52< \\
\mathrm{IET}= \\
59\end{array}$ & Mesotrófico & $\begin{array}{l}\text { Corpos d'água com produtividade intermediária, com possíveis implicações sobre a qualidade da } \\
\text { água, mas em níveis aceitáveis, na maioria dos casos. }\end{array}$ \\
\hline $\begin{array}{ll}59< \\
\mathrm{IET}= \\
63\end{array}$ & Eutrófico & $\begin{array}{l}\text { Corpos d'água com alta produtividade em relação às condições naturais, com redução da } \\
\text { transparência, em geral afetados por atividades antrópicas, nos quais ocorrem alterações } \\
\text { indesejáveis na qualidade da água decorrentes do aumento da concentração de nutrientes e } \\
\text { interferências nos seus múltiplos usos. }\end{array}$ \\
\hline $\begin{array}{l}63< \\
\mathrm{IET}= \\
67\end{array}$ & Supereutrófico & $\begin{array}{l}\text { Corpos d'água com alta produtividade em relação às condições naturais, de baixa transparência, } \\
\text { em geral afetados por atividades antrópicas, nos quais ocorrem com frequência alterações } \\
\text { indesejáveis na qualidade da água, como a ocorrência de episódios florações de algas, e } \\
\text { interferências nos seus múltiplos usos. }\end{array}$ \\
\hline$>67$ & Hipereutrófico & $\begin{array}{l}\text { Corpos d'água afetados significativamente pelas elevadas concentrações de matéria orgânica e } \\
\text { nutrientes, com comprometimento acentuado nos seus usos, associado a episódios florações de } \\
\text { algas ou mortandades de peixes, com consequências indesejáveis para seus múltiplos usos, } \\
\text { inclusive sobre as atividades pecuárias nas regiões ribeirinhas. }\end{array}$ \\
\hline
\end{tabular}

Fontes: CETESB (2007); LAMPARELLI (2004).

Os parâmetros foram coletados e analisados segundo as recomendações do Standard Methods for the Examination of Water and Wastewater (APHA, 2005). Por fim, os resultados encontrados foram tabulados e expressos por meio de gráficos para melhor análise e discussão.

A perspectiva do desafio ambiental, quase em sua totalidade, foi apoiada sob o lastro teórico de Porto-Gonçalves (2004), bem como, outras literaturas, que foram utilizadas para promoção de uma reflexão teórica sobre a problemática da eutrofização, que está vinculada à aspectos de natureza antrópica, que tem afetado a qualidade do meio ambiente.

A escolha dessa abordagem teórica-reflexiva se dá em função dos apontamentos que são realizados sobre a questão do meio ambiente, lançando luz sobre o desafio ambiental, que especificamente será apoiado aos recursos hídricos. Portanto, a reflexão adotada, em parte da discussão se fundamentaram nas ideias da Teoria social a fim de compreender o ambiente e as dinâmicas nelas expressas (Ferreira 2010).

\section{RESULTADOS E DISCUSSÃO}

A partir das campanhas de monitoramento realizadas durante o Programa Água Azul, foi possível inferir o estado trófico dos mananciais superficiais da Bacia Hidrográfica do Rio Apodi-Mossoró. Estudos com esse perfil fazem-se extremamente importantes para sociedade, visto que se revestem de caráter social, ambiental e político.

De acordo com o levantamento realizado no Açude Pau dos Ferros, foi observado que o mesmo se 
apresentou quase sempre com elevadíssimo índice de eutrofização, representado pela média IET resultante em Hipereutrófico (Figura 1). Esse fato pode estar relacionado ao nível de exposição do Açude Pau dos Ferros a atividade agropecuária na região, o que influencia diretamente no fator qualidade da água.

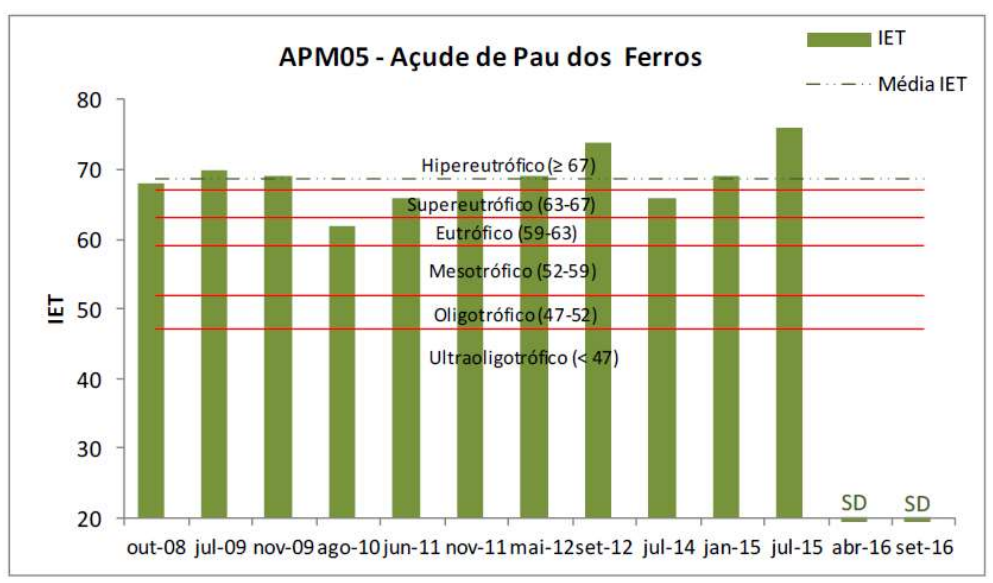

Figura 1: Histórico do IET da água no Açude de Pau dos Ferros (APM05) (SD-Sem dado).

Determinados processos como o de eutrofização do solo são relacionados de forma direta com a presença de compostos de nitrogênio, como: amônia, óxidos de nitrogênio (presentes em fertilizantes utilizados na agricultura), para dinamizar o crescimento e desenvolvimento de algumas culturas como o milho (HANACLETO et al., 2016).

De acordo com o trabalho de Morais Neto (2018) relata que as atividades agropecuárias na região do semiárido realizadas em solos expostos elevam as concentrações de nitrogênio e fósforo totais nos reservatórios, favorecendo o processo de eutrofização, uma vez que fornece excesso de nutrientes necessários para o desenvolvimento de cianobactérias.

A densidade média de cianobactérias do Açude Pau dos Ferros foi de 717.422 cél./mL (Figura 2), denotando elevado índice, no qual predominaram as espécies Cylindrospermopsis raciborskii (produtora de cianotoxinas) e Planktolyngbya minor. Com a exceção de Julho de 2014, os demais resultados se apresentaram sempre acima do VLP pela resolução CONAMA e Ministério da Saúde (MS). Além disso, foram detectados elevados níveis de metais tóxicos, como cobre, níquel e mercúrio na água, contribuindo ainda mais para sua degradação.

Os metais, de fato, acabam contribuindo com a degradação de corpos hídricos. Estudos apontam que os metais, em níveis mais elevados, promovem efeitos tóxicos crônicos e agudos sobre a saúde humana e nos ecossistemas (GARCIA, 2011). Contudo o clima semiárido da região favorece os altos índices de evaporação e à escassez de água, conforme dados pluviométricos de alguns municípios distribuídos ao longo da bacia (OLIVEIRA, 2009), propiciando um cenário ideal para a aceleração do processo de eutrofização, como o que foi observado no Açude de Pau dos Ferros.

Quanto ao histórico do IET, a média para o Açude Lucrécia resultou em Supereutrófico (Figura 3), inferindo assim elevado grau de eutrofização. Assim como no ponto anterior, este manancial possui contaminação agravada, tendo em vista seus múltiplos usos e potencial para a região. Esse açude possui ainda alto uso agropastoril, sofrendo assim forte impacto hídrico mediante essa atividade. 


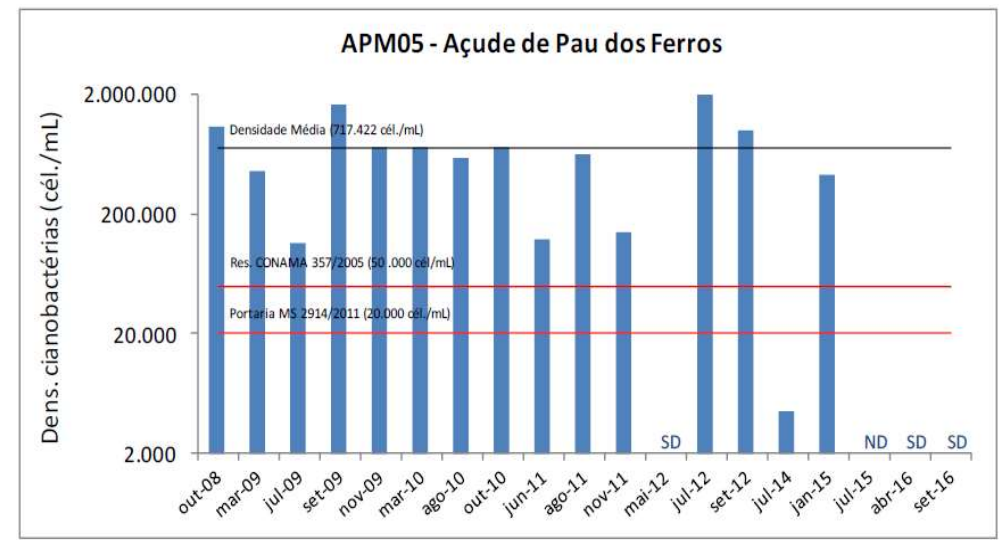

Figura 2: Histórico da Densidade de Cianobactérias da água no Açude de Pau dos Ferros (APM05) (SD-Sem dado).

No Açude Lucrécia, de acordo com Garcia (2011), o principal uso das águas desse reservatório possui fins domésticos, entretanto, em decorrência do constante aumento populacional, aliado a ausência de planejamento em políticas públicas, os esforços de preservação do açude não têm sido eficientes para manter a qualidade de suas águas ao longo dos anos. Ainda de acordo com esta autora, o aumento expressivo do descarte de dejetos tanto no solo, na água ou atmosfera permite que diferentes grupos químicos sejam dispersos no ambiente e consequentemente gerando estresse ambiental, prejudicando as atuais e futuras gerações de seres vivos, além dos próprios seres humanos.

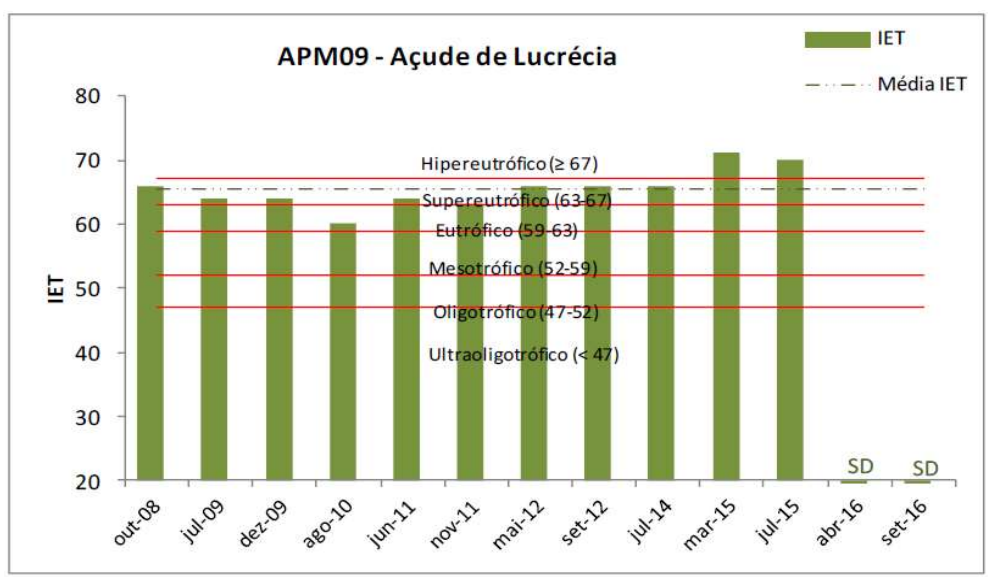

Figura 3: Histórico do IET da água no Açude de Lucrécia (APM09) (SD-Sem dado).

Segundo Marcon et al. (2010), soma-se a ação de descargas antropogênicas originadas de despejo de esgoto doméstico e contaminação ocasionada pelos agrotóxicos, o fato de que o Açude de Lucrécia tem apresentado contaminação por metais tóxicos e cianobactérias potencialmente tóxicas (MARCON et al., 2010). Ainda de acordo com os trabalhos desses autores, análises realizadas neste reservatório mostraram níveis acima do permitido pelo CONAMA para os metais Cádmio, Cobre, Manganês, Zinco, Cromo e Níquel. Além desses metais, nutrientes são adicionados ao reservatório por meio da ação antropogênica (GARCIA, 2011), o que favorece a proliferação das cianobactérias.

A predominância de cianobactérias encontradas se deu a partir das seguintes espécies: Cylindrospermopsis raciborskii (produtora de cianotoxinas), Planktolyngbya sp e Planktolyngbya minor. Foi observado que em todas as campanhas os valores encontrados ultrapassaram a Portaria 2914/2011 do MS e apenas em Junho de 2011 não ultrapassou a CONAMA. Essa elevada densidade pode ser vista a partir do 
número médio encontrado 995.719 cél/mL (Figura 4) ao longo dos anos.

Devido às condições ambientais da área do Açude Lucrécia, como nas demais áreas semelhantes do semiárido nordestino, o aumento dessa biomassa é favorecido justamente pelas características de redução do volume de água e a reduzida profundidade dos reservatórios no período de estiagem, que acabam promovendo uma turbidez mais elevada e consequente, diminuição da penetração da luz (OLIVEIRA, 2015), este fator acaba interferindo no equilíbrio ecológico do corpo hídrico, levando a perda de espécies.

O volume hídrico desse reservatório regularmente se encontra baixo por motivo de escassez de chuva, o que resulta na aceleração do processo de eutrofização e acúmulo de poluentes como os metais advindos de efluentes agropecuários e domésticos, além de fonte natural através da lixiviação de solos cristalinos (SERRA, 2006). Em consonância com este último argumento, a questão da baixa pluviosidade no semiárido já é em si um fator que gera alta vulnerabilidade e que, somada ao uso de terras de solo exposto com elevado potencial de escoamento, tende a aumentar ainda mais vulnerabilidade diante de um processo de eutrofização (MORAIS NETO, 2018).

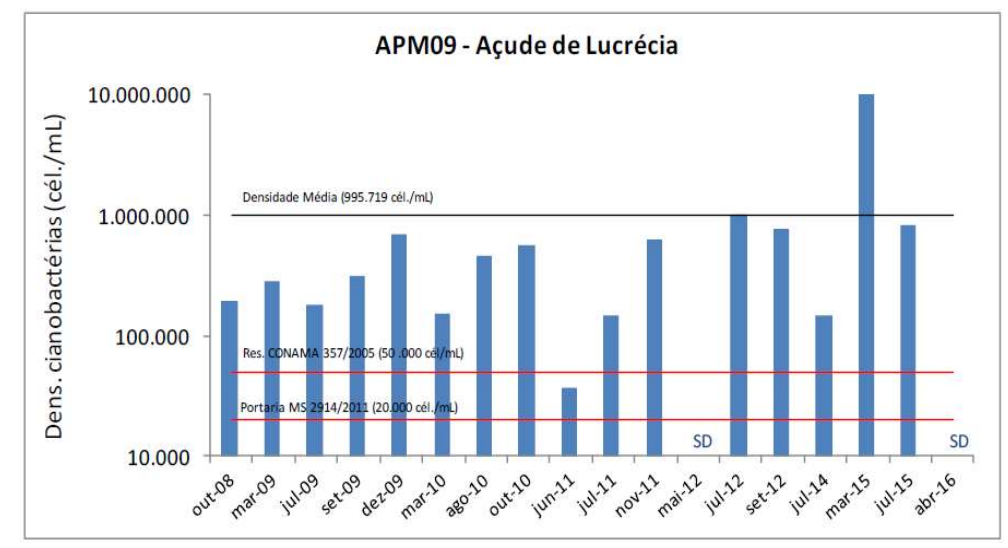

Figura 4: Histórico da Densidade de Cianobactérias da água no Açude de Lucrécia (APM09) (SD-Sem dado). Fonte: IGARN (2016).

Historicamente, a partir das campanhas realizadas, o Índice de Estado Trófico resultou em uma média Supereutrófico, também indicando elevado grau de eutrofização no Açude Rodeador (Figura 5). Neste reservatório hídrico, encontra-se o mesmo problema agropastoril que infere contaminação.

De acordo com Braga et al. (2015), no estado do Rio Grande do Norte, os reservatórios hídricos como açudes têm sido submetidos a eutrofização e florações frequentes de cianobactérias potencialmente tóxicas. O que, em virtude das características da região do semiárido, pode ser considerado como consequência dos processos naturais, mas que inviabiliza o uso de seus recursos hídricos, segundo os dados da Portaria no 2.914/2011 do Ministério da Saúde, que preconiza que a ocorrência de espécies potencialmente tóxicas está ligada a perda de qualidade da água (BRASIL, 2011). Somado a isto ao fato de que, assim como nos demais açudes citados, o Açude Rodeador também apresenta essa característica de uso e ocupação indevidos e de forma desordenada do solo. 


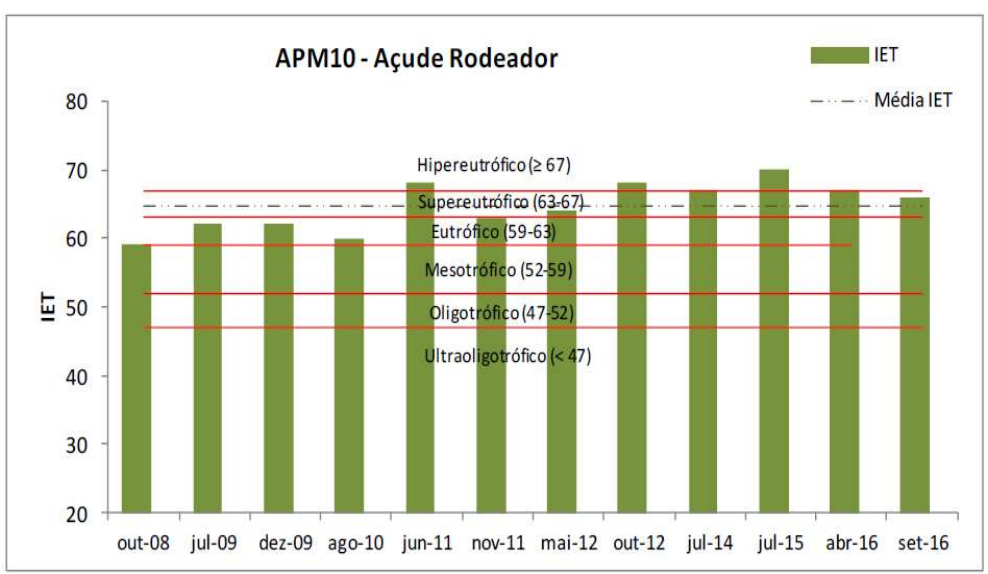

Figura 5: Histórico do IET da água no Açude Rodeador (APM10).

Esse tipo de atividade é bastante comum no semiárido do nordeste brasileiro em áreas de agricultura e pecuária familiares, gerando um cenário de intensa exploração (COELHO et al., 2014). O fato dos solos nos arredores do Açude Rodeador, e os demais reservatórios analisados neste trabalho estarem sujeitos ao clima do semiárido, agrava esse cenário de eutrofização, pois, segundo estudos de Morais Neto (2018), o aumento de áreas impermeáveis com o solo exposto e consequentemente intensidade mais elevada de escoamento superficial ao longo de corpos hídricos, favorece a lixiviação em áreas de atividades antrópicas, como áreas de agricultura e pecuária, elevando as concentrações de nitrogênio total e fósforo total nos reservatórios.

O quantitativo médio das cianobactérias (632.030 cél./mL) foi muito superior ao VLP da Resolução CONAMA 357/2005 (50.000 cél./mL) e da Portaria MS 2914/2011 (20.000 cél./mL), como pôde ser visto na Figura 6. Com isso observou-se a predominância das espécies: Aphanizomenon gracile (produtora de toxinas), Aphanocapsa incerta (não produtora de toxinas), Aphanocapsa elachista (não produtora de toxinas), Cilindrospermopsis raborskii (produtora de toxinas), Merismopedia tenuissima (não produtora de toxinas).

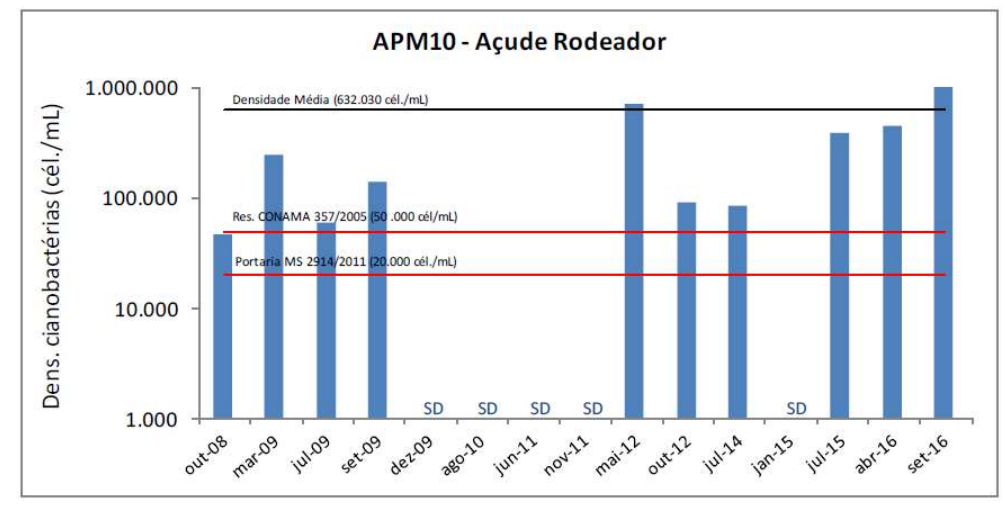

Figura 6: Histórico da Densidade de Cianobactérias da água no Açude Rodeador (APM10) (SD-Sem dado).

As cianobactérias dos gêneros Aphanizomenon e Cilindrospermopsis foram relacionadas como produtoras de neurotoxinas (de ação rápida) e hepatotoxinas (de ação mais lenta), que podem causar danos graves tanto para a vida animal quanto para a saúde humana (BRASIL, 2015). Por exemplo, quando são encontradas em águas utilizadas para fins recreativos e/ou de consumo, podendo ser consideradas como os principais agentes tóxicos que são produzidos por cianobactérias (BRASIL, 2015).

Uma forma de mitigar os efeitos desse problema de eutrofização nos reservatórios da bacia 
hidrográfica do Rio Apodi-Mossoró é a criação do plano de contingenciamento para o controle da floração das cianobactérias potencialmente nocivas, se faz necessário apresentar diferentes aspectos, desde a regulamentação dos usos do solo e dos recursos hídricos mediante a detecção da presença das cianobactérias potencialmente nocivas e/ou cianotoxinas na água. O plano envolve algumas etapas básicas: (i) monitoramento e (ii) gerenciamento (CETESB, 2013).

No primeiro item, deve existir o acompanhamento gradual da floração das cianobactérias, identificar a concentração de cianotoxinas na água, para isso é recomendado realizar coletas para a identificação das espécies que são potencialmente nocivas para proposição de medidas específicas, para o segundo item é necessário a suspensão temporária do uso da água contaminada, caso exista a detecção na etapa anterior, até a contenção da floração, a partir das técnicas preconizadas na literatura pertinente (BRASIL, 2003).

Uma medida que pode ser adotada, embora demande um alto investimento financeiro seria a criação de Estação de Tratamento de Água (ETA) com tecnologias para a detecção e eliminação da cianotoxina presente na água, caso ela esteja presente. As ETA's que fazem o tratamento convencional apresentam falhas por promover a lise celular das cianotoxinas, portanto a criação de ETA's com equipamentos apropriados e profissionais qualificados seriam possíveis a(s) remoção(ões) do(s) agente(s) potencialmente patogênico(s), sem promover a lise celular. As recomendações para a instalação das ETA's apropriadas devem seguir as recomendações de Brasil (2003).

Inicialmente, vale mencionar que a qualidade ambiental dos recursos hídricos se torna um aspecto de extrema importância, tendo em vista, as características da região do semiárido, por ser espaço dotado de fatores ambientais e climáticos, que naturalmente, proporcionam a escassez hídrica. No entanto, a perspectiva da seca no Nordeste brasileiro, sobretudo, no semiárido potiguar é compreendido a partir da "indústria da seca", conceito dotado de caráter político e ideológico, ou seja, a partir de uma análise sociológica é possível compreender a escassez hídrica como projeto político, pautado na lógica de subjugação do Nordeste, que historicamente sofre com as secas, marcando esse território como um lugar que é sinônimo de atraso (SILVA, 2003).

Nesse sentido, Rodrigues (1998) destaca que "a questão ambiental deve ser compreendida como produto da intervenção da sociedade sobre a natureza. Diz respeito não apenas a problemas relacionados à natureza, mas às problemáticas decorrentes da ação social". Portanto, em se tratando da qualidade ambiental dos recursos hídricos dos açudes inqueridos neste trabalho, é possível inferir que as atividades humanas têm contribuído, não só para o agravamento da eutrofização, mas também para o reforço da indústria da seca, expresso nos argumentos mobilizados por Silva (2003).

Assim, é importante considerar a afirmação de Porto-Gonçalves (2004) que:

A problemática ambiental é, sobretudo, uma questão de ordem ética, filosófica e política é desviar de um caminho fácil que nos tem sido oferecido: o de que devemos nos debruçar sobre soluções práticas, técnicas, para resolver os agraves problemas de poluição, desmatamento e erosão.

Desta forma, é possível considerar que a problemática da eutrofização, é muitas vezes vinculado a técnicas apoiadas nas ideias científicas, como bem foi demonstrado no plano de contingenciamento (CETESB, 
2013), como se a técnica e a ciência fossem capazes de solucionar o problema. No entanto, Porto-Gonçalves (2004) tece críticas sobre este tema, ao afirmar que o sistema técnico traz em si as incoerências da sociedade que o criou, desta forma, a crença acrítica na solução técnica para a problemática da qualidade da água não pode recair nessa visão ingênua, que teve origem na Revolução industrial e apoiadas nas ideias iluministas, de uma ciência capaz de solucionar todos os agraves ambientais.

Como foi constatado, existem atividades antrópicas que buscam fazer do território um espaço com atividades econômicas específicas, uma vez que o entorno dos reservatórios tem áreas destinadas as atividades agropecuárias, fazendo uso, inclusive, de fertilizantes químicos. Isso revela uma lógica pautada na ideia da globalização neoliberal, que em função da pressão capitalista, enxerga esse espaço como área potencial à ser dominada e domesticada, capaz de alimentar o capitalismo, isso fica evidente através da ocorrência dos agroquímicos e as empresas que fazem uso do espaço, bem como, dos recursos hídricos para manterem a produção de fruticultura irrigada na região, desta forma dando outro caráter social (PORTOGONÇALVES, 2004).

O desafio ambiental é justamente tentar incorporar a dimensão ambiental nos processos desenvolvimento, para que não recaia sobre a ideologia capitalista, por enxergar o espaço apenas como recurso a ser explorado. É importante ainda considerar feições contraditórias da sociedade, uma vez que essas dimensões dos problemas ambientais acabam ocultando algumas questões.

Nesse sentido, Rodrigues (1998) contribui ao afirmar que:

Os problemas ecológicos parecem, à primeira vista, referir-se apenas às relações homem/natureza e não às relações dos homens entre si. É preciso, assim, ter cuidado para não ocultar a existência e as contradições de classes sociais para compreender a problemática ambiental em sua complexidade, pois os problemas ambientais dizem respeito a forma como o homem em sociedade se apropria da natureza.

Contudo, "a dinâmica da sociedade capitalista quando considerada na sua inscrição territorial enfim, na sua materialidade -, mostra, além de sua insustentabilidade ambiental, sua insustentabilidade política" (PORTO-GONÇALVES, 2004). Mediante a isso, é necessária uma nova forma de mentalidade, que neste sentido, Leff (2009) chama de racionalidade ambiental, destacando caminhos a partir da incorporação teórica da abordagem do diálogo de saberes. Estes dois conceitos por sua vez, são dotados de pressupostos que apontam o caminho para promoção de um desenvolvimento que resguarda a ideia de autonomia, liberdade e igualdade (LEFF, 2009; PORTO-GONÇALVES, 2004).

A lógica dessa apropriação do espaço, muitas vezes é marcado de maneira ambígua e irracional, colocando em risco a qualidade ambiental. No caso dos reservatórios, a eutrofização é um aspecto que se configura um risco, já que existem o crescimento excessivo da população de cianobactérias, incluindo espécies potencialmente produtoras de cianotoxinas, e a ingestão da água contaminada é um problema grave de saúde pública, como bem foi demonstrado nos dispositivos jurídicos (BRASIL, 2011; BRASIL, 2005; CETESB, 2013).

\section{CONCLUSÕES}

Como foi apresentado nos dados acima, os principais reservatórios usados para abastecimento 
humano da Bacia Hidrográfica do Rio Apodi-Mossoró encontraram-se com IET elevados, colocando em risco a integridade ambiental, o equilíbrio ecológico, bem como, a saúde humana em perigo. O Açude Pau dos Ferros foi o que apresentou o maior IET, categorizado como média Hipereutrófico, enquanto os açudes Lucrécia e Roeador ficou com média Supereutrófico. Além disso, os dados sobre densidade de cianobactérias se mostraram quase em sua totalidade acima das normas impostas pela Portaria 2914/2011 do Ministério da Saúde e da Resolução 257/2005 do CONAMA.

A análise da diversidade fitoplanctônica demonstraram a ocorrência de algumas espécies potencialmente produtoras de cianotoxinas, o que reforça a atenção das autoridades competentes sobre os aspectos de qualidade das águas dos reservatórios analisados. É importante destacar que o problema da eutrofização nos reservatórios usados para abastecimento público no estado do Rio Grande do Norte está ligado às características naturais e climáticas, tendo em vista, o tipo de solo e seus nutrientes, as temperaturas elevadas, o nível de incidência solar, a propriedade dos açudes apresentarem o aspecto lêntico da água, que são em sua particularidade fatores que já propiciam a eutrofização naturalmente.

Todavia, é importante destacar que as atividades agropecuárias tem afetado de forma direta esses corpos hídricos, potencialmente acelerando o crescimento da biomassa do fitoplâncton, especialmente, as cianobactérias, isso está ligado à fatores como uso de agroquímicos que aumentam a fertilidade do solo, e em períodos de chuva, esses nutrientes são lixiviados para os açudes, desta forma, o fitoplâncton crescem exponencialmente pela entrada de fósforo e nitrogênio que são incorporados na biomassa algal.

Em suma, a teoria social dispõe de conceitos que contribuem na reflexão teórica sobre a questão do meio ambiente dentro da perspectiva do desafio ambiental, e com isso, tem revelado que muitos problemáticas de ordem ecológica, como é o caso da eutrofização, tem ligação com as atividades humanas que estão pautadas na lógica da globalização da natureza que visa domina-la, desta forma, colocando em risco as espécies biológicas que estão diretamente dependentes desse recurso.

\section{REFERÊNCIAS}

APHA. American Public Health Association. Standard methods for the examination ofwater and watwater. $21 \mathrm{ed}$. Washington: APHA, 2005.

BRAGA, G. G.; BECKER, V.; OLIVEIRA, J. N. P.; MENDONÇA JUNIOR, J. R.; BEZERRA, A. F. M.; TORRES, L. M.; GALVÃO, A. M. F.; MATTOS, A.. Influence of extended drought on water quality in tropical reservoirs in a semiarid region. Acta Limnologica Brasiliensia, v.27, n.1, p.15-23, 2015.

BRASIL. Cianobactérias tóxicas na água para consumo humano na saúde pública e processos de remoção em água para consumo humano. Brasília: Fundação Nacional de Saúde, 2003.

BRASIL. Ministério da Saúde, Secretaria de Vigilância em Saúde, Departamento de Vigilância em Saúde Ambiental e Saúde do Trabalhador. Cianobactérias/cianotoxinas: procedimentos de coleta, preservação e análise. Brasília: Ministério da Saúde, 2015.
BRASIL. Ministério da Saúde. Portaria n. 2.914. Brasília: Ministério da Saúde, 2011.

BRASIL. Ministério do Meio Ambiente. Resolução CONAMA 357/2005. Brasília: DOU, 2005.

CETESB. Companhia Ambiental do Estado de São Paulo. Relatório de Qualidade das Águas Interiores no Estado de São Paulo. São Paulo: CETESB, 2007.

CETESB. Companhia Ambiental do Estado de São Paulo. Manual de cianobactérias planctônicas: legislação, orientações para o monitoramento e aspectos ambientais. São Paulo: CETESB, 2013.

COELHO, V. H. R.; MONTENEGRO, S. M. G. L.; ALMEIDA, C. N.; LIMA, E. R. V.; RIBEIRO NETO, A.; MOURA, G. S. S.. Dinâmica do uso e ocupação do solo em uma bacia hidrográfica do semiárido brasileiro. Revista Brasileira de Engenharia Agrícola e Ambiental, v.18, n.1, p.64-72, 2014. 
GARCIA, A. C. F. S.. Avaliação do potencial mutagênico da água do açude de Lucrécia (RN-Brasil): um enfoque na relação saúde e ambiente. Dissertação (Mestrado em Desenvolvimento e Meio Ambiente) - Universidade Federal do Rio Grande do Norte, Natal, 2011.

HANACLETO, N.; CARVALHO, G. A.; SILVA, B. A. H.. Análise dos impactos do cultivo do milho por meio da análise do ciclo de vida (ACV). In: SIMPÓSIO DE ENGENHARIA DE PRODUÇÃO. Anais. 2016.

LAMPARELLI, M. C.. Grau de trofia em corpos d'água do estado de São Paulo: avaliação dos métodos de monitoramento. Tese (Doutorado em Ecologia) Universidade de São Paulo, São Paulo, 2004.

LEFF, E.. Complexidade, Racionalidade Ambiental e Diálogo de Saberes. Educação e Realidade, v.34, n.3, 2009.

MARCON, A. E.; FERREIRA, D. M.; MOURA, M. F. V.; CAMPOS, T. F. C.; AMARAL, V. S.; AGNEZ-LIMA, L. F.; MEDEIROS, S. R. B.. Genotoxic analysis in aquatic environment under influence of cyanobacteria, metal and radioactivity. Chemosphere, v.81, n.6, p.773-780, 2010.

MORAIS-NETO, J. V.. Áreas de solo exposto intensificam o processo de eutrofização no semiárido brasileiro. Dissertação (Mestrado em Engenharia Sanitária) Universidade Federal do Rio Grande do Norte, Natal, 2018.
OLIVEIRA, A. K. G.. Alteração das concentrações de nitrogênio e fósforo na bacia do Rio Apodi-Mossoró em função dos efeitos da estiagem e espacialidade. Revista Química: Ciência, Tecnologia e Sociedade, v.4, n.1, 2015.

OLIVEIRA, T. M. B. F.; SOUZA, L. S.; CASTRO, S. S. L.. Dinâmica da série nitrogenada nas águas da bacia hidrográfica Apodi/Mossoró - RN - Brasil. Revista Eclética Química, v.34, n.3, 2009

PORTO-GONÇALVES, C. W.. O Desafio ambiental. Os porquês da desordem mundial. Mestres explicam a globalização. Rio de Janeiro: Record, 2004.

RODRIGUES, A. M.. Produção e consumo do e no espaço: problemática urbana. São Paulo: Hucitec, 1998.

SEMARH. Secretária de Estado do Meio Ambiente e dos Recursos Hídricos. Cadastramento e nivelamento de poços do Aquífero Barreiras no Município de Natal/RN. Relatório final. SEMARH, 2006.

SERRA, C. V.. Abordagem humana integrada a estudos de uma problemática ambiental no interior do Rio Grande do Norte. Dissertação (Mestrado em Planejamento e Gestão Ambiental) - Universidade Católica de Brasília, Brasília, 2006.

SILVA, R. M. A.. Entre dois paradigmas: combate à seca e convivência com o semiárido. Sociedade e Estado, v.18, n.12, 2003.

A CBPC - Companhia Brasileira de Produção Científica (CNPJ: 11.221.422/0001-03) detém os direitos materiais desta publicação. Os direitos referem-se à publicação do trabalho em qualquer parte do mundo, incluindo os direitos às renovações, expansões e disseminações da contribuição, bem como outros direitos subsidiários. Todos os trabalhos publicados eletronicamente poderão posteriormente ser publicados em coletâneas impressas sob coordenação da Sustenere Publishing, da Companhia Brasileira de Produção Científica e seus parceiros autorizados. Os (as) autores (as) preservam os direitos autorais, mas não têm permissão para a publicação da contribuição em outro meio, impresso ou digital, em português ou em tradução. 